\title{
PKC Activation Promotes Internalization of DNA-Immobilized Inorganic Nano-Crystals by Clathrin-Dependent Endocytosis for Efficient Transgene Expression in Human Lymphocytes
} Nag $\mathrm{K}^{1 \#}$, Hossain $\mathrm{S}^{1 \#}$, Sultana $\mathrm{N}^{1 \#}$ and Chowdhury $\mathrm{EH}^{2 *, \#}$

${ }^{1}$ Graduate School of Bioscience and Biotechnology, Tokyo Institute of Technology, 4259 Nagatsuta-cho, Midori-ku, Yokohama 226-8501, Japan 2 Jeffrey Cheah School of Medicine and Health Sciences, Monash University Sunway Campus, Jalan Lagoon Selatan, Bandar Sunway, Selangor Darul Ehsan, Malaysia ${ }^{\#}$ All the authors contributed equally

\begin{abstract}
Leukemia and lymphoma cells are potential targets in cancer therapy for genetic manipulation either by transgene expression or silencing of endogenous gene expression. In addition, genetically engineered autologous lymphocytes expressing a chimeric antigen against a receptor overexpressed in tumor or tumor vasculature are promising cellbased therapeutics for cancer. The major hurdle to the successful implementation of these attractive approaches is the lack of a smart device for efficient transgene delivery and expression in the lymphocytes. Recently, we developed an efficient nanocarrier of carbonate apatite for intracellular delivery and release of DNA molecules, achieving very high level of transgene expression in primary as well as cancer cell lines. However, its efficacy in human T leukemia cells is comparatively low. Here, we reveal that simultaneous stimulation of human $\mathrm{T}$ leukemia cells by the most commonly used phorbol ester-based protein kinase $\mathrm{C}$ (PKC) activator and an actin filament disrupting agent dramatically enhanced carbonate apatite-mediated transgene delivery and expression in the cells by synergistically activating protein kinase $\mathrm{C}(\mathrm{PKC})$, while rapidly extruding $\mathrm{Ca}^{2+}$ of intracellularly dissolved particles through plasma membrance-associated $\mathrm{Ca}^{2+}$ ATPase. Moreover, endocytosis of the DNA-associated particles across the cell membrance was found to follow the clathrin-dependent route in both normal and activated cells. The findings thus offer significant insights for pre-clinical and clinical ex vivo trials of cancer treatment utilizing autologous $\mathrm{T}$ cells.
\end{abstract}

Keywords: Carbonate apatite; Nano-crystals; T-leukemia cell; Radio-labeled calcium; Transfection; DNA uptake; Ca-ATPase; PKC activation; Actin disruption; Endocytosis; Clathrin

Abbreviations: DMEM: Dulbecco's Modified Eagle's Medium; PKC: Protein Kinase C; VEGF: Vascular Endothelial Growth Factor; PMA: Phorbol 12-Myristate 13-Acetate; PAO: Phenylarsine Oxide; RLU: Relative Light Unit

\section{Introduction}

Tumor cells such as leukemia and lymphoma cells are attractive targets for gene-based therapeutics. Gene transfer and expression for cytokine and immunomodulatory molecules in various kinds of tumor cells have been shown to mediate tumor regression and antimetastatic effects [1-4]. Genetically modified leukemia cells expressing costimulatory molecules are likely to have significant therapeutic roles for patients with leukemia [5]. Mouse T cells genetically engineered to express a chimeric antigen against human ErbB-2 receptor, a protein overexpressed by many tumors [6] or VEGFR-2, a protein overexpressed in tumor vasculature and responsible for tumor progression and metastasis [7], caused total regression of ErbB-2-expressing tumors [6] or significantly inhibited the growth of syngeneic tumors in mice and prolonged the survival of mice [7], respectively. Genetically modified autologous $\mathrm{T}$ lymphocytes transduced with the human adenosine deaminase deficiency (ADA) cDNA led to increased T-lymphocyte counts and improvement of the patient's immune function [8].

The major hurdle to the successful implementation of lymphocytetargeted gene therapy approaches is the lack of an ideal device for transgene delivery and expression with high efficacy, low cytotoxicity and excellent biocompatibility. Although virus-based systems promote efficient gene expression in lymphocytes, recombinant viral treatment is associated with complications due to highly evolved and complex viral biology and/or host-parasite interactions [9]. On the other hand, current nonviral methods or vectors for transfection of hematopoietic cells [2] remain poorly developed in the context of effectiveness or post-treatment cell viability.

Recently, we developed a smart DNA delivery and expression system based on $\mathrm{pH}$-sensitive inorganic nanocrystals of carbonate apatite with capability of effective intracellular delivery and release of associated DNA molecules in cell cytoplasm, leading to very high level of transgene expression both in cancer and primary cells $[10,11]$. However, its efficiency in transfecting human $\mathrm{T}$ cell leukemia cells (jurkat) is relatively poor, although coating of the particle surface electrostatically with naturally occurring fibronectin and/or chimeric E-cadherin-Fc, enhanced transgene delivery in presence of an actin filament disrupter [12]. Here, we report that synergistic stimulation of protein kinase $\mathrm{C}$ (PKC) activation by a traditionally used phorbol ester-based PKC activator and an actin disrupter remarkably enhanced carbonate apatite-assisted transgene delivery and expression into human leukemia cells and facilitated extrusion through plasma membrance-associated $\mathrm{Ca}^{2+}$-ATPase of the intracellular $\mathrm{Ca}^{2+}$ released from dissolution of endocytosed particles. Moreover, internalization of the DNA-associated particles across the cell membrance was directed by the clathrin-dependent pathway in both normal and activated stage of the cells.

*Corresponding author: Chowdhury EH, Jeffrey Cheah School of Medicine and Health Sciences, Monash University Sunway Campus, Jalan Lagoon Selatan, Banda Sunway, Selangor Darul Ehsan, Malaysia, Tel: +603-5514 4978; Fax: +603-5514 6323; E-mail: md.ezharul.hoque@monash.edu

Received April 15, 2013; Accepted May 27, 2013; Published May 29, 2013

Citation: Nag K, Hossain S, Sultana N, Chowdhury EH (2013) PKC Activation Promotes Internalization of DNA-Immobilized Inorganic Nano-Crystals by Clathrin-Dependent Endocytosis for Efficient Transgene Expression in Human Lymphocytes. J Nanomed Nanotechol 4: 174. doi:10.4172/2157-7439.1000174

Copyright: (c) $2013 \mathrm{Nag} \mathrm{K}$, et al. This is an open-access article distributed under the terms of the Creative Commons Attribution License, which permits unrestricted use, distribution, and reproduction in any medium, provided the original author and source are credited. 
Citation: Nag K, Hossain S, Sultana N, Chowdhury EH (2013) PKC Activation Promotes Internalization of DNA-Immobilized Inorganic NanoCrystals by Clathrin-Dependent Endocytosis for Efficient Transgene Expression in Human Lymphocytes. J Nanomed Nanotechol 4: 174. doi:10.4172/2157-7439.1000174

Page 2 of 6

\section{Methods and Materials}

\section{Materials}

Dulbecco's modified Eagle's medium (DMEM) and RPMI medium were purchased from Gibco-BRL whereas propidium iodide (PI), cytochalasin D, phorbol 12-myristate 13-acetate (PMA), staurosporin (St), lanthanum $\left(\mathrm{Ln}^{3+}\right)$ chloride, amantadine and phenylarsine oxide (PAO) were bought from Sigma.

\section{Cell culture, uptake of fluorescence-labeled DNA and transfection}

Jurkat cells were grown in RPMI 1640 medium (Gibco BRL) containing $10 \%$ fetal bovine serum (FBS) and seeded at $5 \times 10^{5}$ cells per well into a 24 -well plate the day before transfection. Then $3 \mu \mathrm{l}$ of $1 \mathrm{M} \mathrm{CaCl}_{2}$ in presence or absence of $1 \mu \mathrm{g}$ of PI was mixed with $2 \mu \mathrm{g}$ of plasmid DNA in $1 \mathrm{ml}$ of freshserum-free $\mathrm{HCO}^{3-}$-buffered DMEM medium ( $\mathrm{pH} 7.5$ ), followed by incubation for $30 \mathrm{~min}$ at $37^{\circ} \mathrm{C}$ for complete generation of DNA/carbonate apatite particles. Medium with generated particles was mixed with $10 \%$ FBS and in some cases, with PMA $(10 \mathrm{nM})$ or cytochalasin D $(1 \mu \mathrm{M})$ or both and added onto the cells in each well immediately after the old RPMI medium had been removed from the well. After incubation for $4 \mathrm{~h}$, the cells were washed with $0.5 \mathrm{mM}$ EDTA in PBS before observation of PI-labeled DNA in cell cytoplasm by a fluorescence microscope or the cells were incubated for $0.5,1,2$ and $4 \mathrm{~h}$ prior to the complete lysis of cell membrane and estimation of luciferase gene expression using a commercial kit (Promega) and photon counting (TD-20/20 Luminometer, Turner BioSystems). Each transfection experiment was done in triplicate, and transfection efficiency was expressed as mean relative light units (RLU) per milligram of cell proteins.

\section{PKC activation assay}

Jurkat cells were treated with the particles (formed by addition of $3 \mu \mathrm{l}$ of $1 \mathrm{M} \mathrm{CaCl}_{2}$ in $1 \mathrm{ml}$ of $\mathrm{HCO}^{3-}$-buffered DMEM medium ( $\mathrm{pH} 7.5$ ), followed by incubation for at $37^{\circ} \mathrm{C} 30 \mathrm{~min}$ ) in presence or absence of either PMA or cytochalasin D or both PMA and cytochalsin D at a final concentration of $10 \mathrm{nM}$ and $1 \mu \mathrm{M}$ for PMA and cytochalasin $\mathrm{D}$, respectively. Staurosporin $(\mathrm{St})$ was added in the incubation reaction at a final concentration of $3 \mathrm{nM}$. At indicated time points medium were removed, and cells were washed 3 times with $10 \mathrm{mM}$ EDTA in ice cold PBS. Cells were immediately processed for PKC activation using PKC radiometric assay kit from Millipore and the data were plotted as pmol/ $\mathrm{min} / \mathrm{mg}$ of proteins against indicated time points $(0-250 \mathrm{~min})$.

\section{Intracellular $\mathrm{Ca}^{2+}$ measurement assay}

Jurkat cells were seeded with serum (10\%)-supplemented RPMI medium in a 12-well plate. After $24 \mathrm{~h}$ cultures, cells were incubated either with radioactive ${ }^{45} \mathrm{Ca}$-particles or ${ }^{45} \mathrm{Ca}^{+2}$ ions (no particles) for 0-30 min with the total of 500,000 radioactive counts added to each well. After $24 \mathrm{~h}$, the cells were treated with radioactive ${ }^{45} \mathrm{Ca}$-particles or in some cases incubated with either radioactive ${ }^{45} \mathrm{Ca}$-particles or ${ }^{45} \mathrm{Ca}^{+2}$ ions (no particles) for $30 \mathrm{~min}$ (with the total of 500,000 radioactive counts added to each well) prior to the treatment with either PMA (10 $\mathrm{nM})$ or cytochalasin $\mathrm{D}(1 \mu \mathrm{M})$ or both and after different time intervals, the media were replenished with the Ca-particles or $\mathrm{Ca}^{+2}$ ion having no PMA or cytochalasin D. Depending on the experimental designs, generation of ${ }^{45} \mathrm{Ca}$-particles and supplementation with $10 \%$ FBS were followed by addition of staurosporin, lanthanum chloride, amantadine or phenylarsine oxide (PAO) before the particle suspension solution was added onto the cells. All the samples were prepared at the same time point at $5 \mathrm{~h}$ post-treatment. All the media were removed and washed twice with ice-cold DMEM, followed by 5 min incubation with $10 \mathrm{mM}$ EDTA in PBS. In one case, reagents like PMA and/or cytochalasin $\mathrm{D}$ were added following $1 \mathrm{~h}$ incubation of the cells with either radioactive ${ }^{45} \mathrm{Ca}$-particles or ${ }^{45} \mathrm{Ca}^{+2}$ ions (no particles) and 3 times washing with $10 \mathrm{mM}$ EDTA in PBS and thus, the cells were maintained in RPMI medium devoid of ${ }^{45} \mathrm{Ca}$ particle. Cells were further washed 4 times with ice cold PBS and lysed with $200 \mu \mathrm{l}$ of $500 \mathrm{mM} \mathrm{NaOH}$. Total lysates were blotted on a cellulose membrane and dried overnight in an air chamber at $45^{\circ} \mathrm{C}$. The dried cellulose membranes were subjected for radioactivity measurement in a liquid scintillation counter (Beckman 2000). The values of the CPM represented the intracellular ${ }^{45} \mathrm{Ca}^{+2}$.

\section{Results and Discussion}

\section{Influences of PKC activation and actin disruption in carbonate apatite-mediated transfection}

The cell transfection route of carbonate apatite nano-carrier sequentially involves plasmid DNA condensation with it, interaction of the resulting complex with cell membrane for endocytosis and endosomal escape and nuclear translocation of the DNA for gene expression [10,11]. While the interaction between the DNA and the carrier is based on ionic interactions, the subsequent binding of the complex having 'cation-rich domains' and surface coating of serum proteins including fibronectin, with the cell membrane is apparently assisted by cell-surface anionic proteoglycans (syndecans) and integrins, respectively [13-16]. However, when a human T-cell leukemia cell line (Jurkat) was investigated as the potential target for in vitro transgene delivery study using carbonate apatite particles, both cellular uptake of PI-labeled DNA ( $4 \mathrm{~h})$ at $4 \mathrm{~h}$ and time-dependent (0.5$4 \mathrm{~h}$ ) expression of luciferase gene (Figure 2) were found substantially higher in T lymphoma cells treated with PMA, a PKC activator [17] in comparison with untreated cells, suggesting that serum protein-coated apatite particles could bind the plasma membrane of the activated cells through VLA4/VLA5 integrins [18] and syndecan-2,-4 [19] which are, respectively, activated and expressed in response to lymphoma cell activation by PMA $[18,19]$. Because of the tremendous roles of actin cytoskeletal dynamics in T cell activation [20], we also checked the effect of cytochalasin D (Cyt D) as an actin filament disrupter on modulating uptake of DNA and transfection efficacy of carbonate apatite in the lymphoma cells.

As shown in Figures1 and 2, while no further increase in DNA uptake and luciferase expression was observed for the cells treated with Cyt $\mathrm{D}$, a robust increase both in uptake and expression was confirmed for the combined treatment of PMA and Cyt D, indicating that actin disruption might somehow synergize with PKC activation in enhancing the transfection efficiency.

\section{PKC activation assay during cellular uptake of particles in presence of PMA, cyclosporine and CytD}

In order to elucidate the mechanism for the high transgene expression of apatite carrier system due to the presence of PMA and also, PMA and Cyt D, the T lymphoma cells were incubated with the apatite particles along with PMA, Cyt D and staurosporin (St) either individually or in combinations before harvesting the cells at different time points ( $0-250 \mathrm{~min})$ for PKC assay. As shown in Figure 3, there was a slight increase in PKC activity even for the particles with the highest peak observed at $30 \mathrm{~min}$, which was probably owing to dissolution of the internalized particles in endosomal acidic $\mathrm{pH}[10,11]$ releasing $\mathrm{Ca}^{2+}$ for PKC activation, whereas Cyt D treatment caused no increase in 
Citation: Nag K, Hossain S, Sultana N, Chowdhury EH (2013) PKC Activation Promotes Internalization of DNA-Immobilized Inorganic NanoCrystals by Clathrin-Dependent Endocytosis for Efficient Transgene Expression in Human Lymphocytes. J Nanomed Nanotechol 4: 174. doi:10.4172/2157-7439.1000174

Treated cells

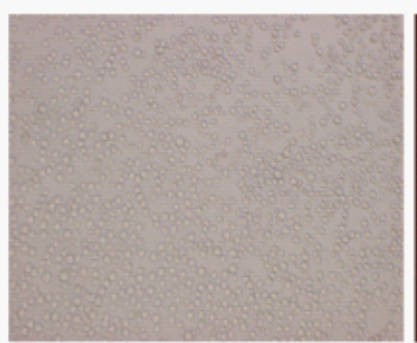

Nanoparticles
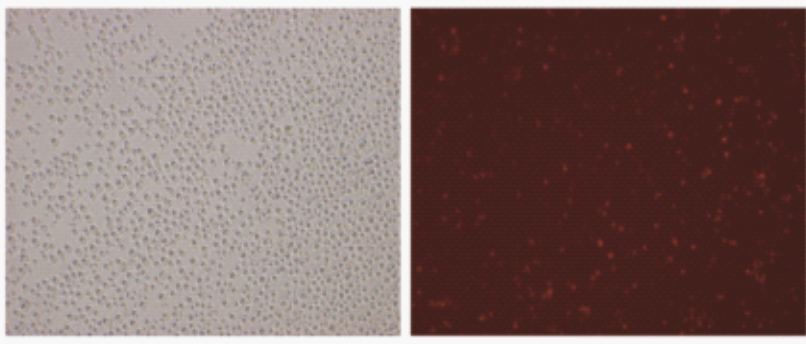

Nanoparticles+Cyt D
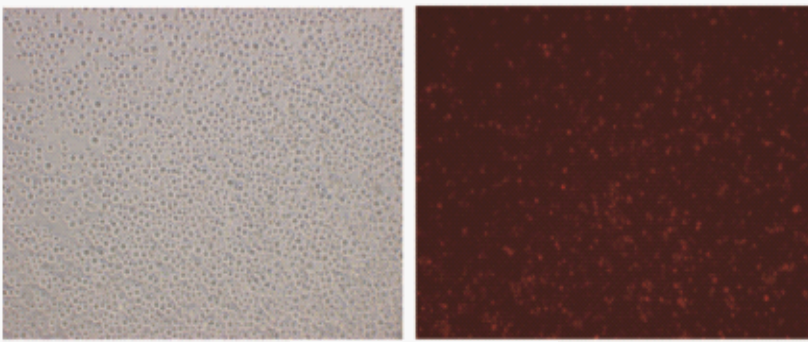

Nanoparticles+PMA
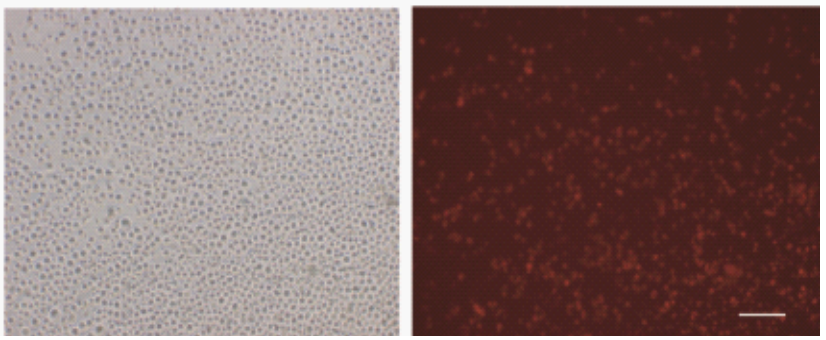

Figure 1: PMA and cytochalasin D treatment enhanced Ca-apatite mediated transgene delivery in T-lymphocytes. DNA/carbonate apatite particles were prepared by mixing $3 \mu \mathrm{l}$ of $1 \mathrm{M} \mathrm{CaCl}_{2}$ and $2 \mathrm{ug}$ of reporter plasmid DNA in presence or absence of $1 \mu \mathrm{g}$ of $\mathrm{Pl}$ in $1 \mathrm{ml}$ of fresh serum-free $\mathrm{HCO}^{3-}$-buffered DMEM medium ( $\mathrm{pH} 7.5$ ), followed by incubation for 30 min at $37^{\circ} \mathrm{C}$ and mixing with $10 \%$ FBS and subsequently with PMA $(10 \mathrm{nM})$, cytochalasin $\mathrm{D}(1 \mu \mathrm{M})$ or both. The particle suspension was added onto the cells in each well immediately after the old RPMI medium had been removed from the well. After incubation for $4 \mathrm{~h}$, the cells were washed with $0.5 \mathrm{mM}$ EDTA in PBS before observation of $\mathrm{PI}$-labeled DNA in cell cytoplasm by a fluorescence microscope. Bar indicates $50 \mu \mathrm{M}$.

the overall activity of PKC in most part of the timeline. As expected, a significant increase in PKC activity was observed for PMA treatment with the sharp peak of the activity equivalent to $\sim 100 \mathrm{pmol} / \mathrm{min} / \mathrm{mg}$ of protein identified at $30 \mathrm{~min}$. However, the combination of PMA and Cyt D surprisingly led to the notable increase in the activity for all the time points with the highest peak of the activity being $\sim 200 \mathrm{pmol} / \mathrm{min} /$ $\mathrm{mg}$ of protein at $60 \mathrm{~min}$ while a decline in the activity roughly by $50 \%$ was noticed for the same combination (PMA and Cyt D) due to St, an inhibitor of PKC, thus suggesting that the high transgene delivery efficacy of carbonate apatite in presence of PMA and Cyt D (Figures 1 and 2) could be attributed to their synergistic effects in enhancing the PKC activity and consequently activating VLA4/VLA5 integrins [18] as well as expressing syndecan-2,-4 [19] for facilitation of endocytosis of serum protein-coated particles [13-16] (Figure 3).

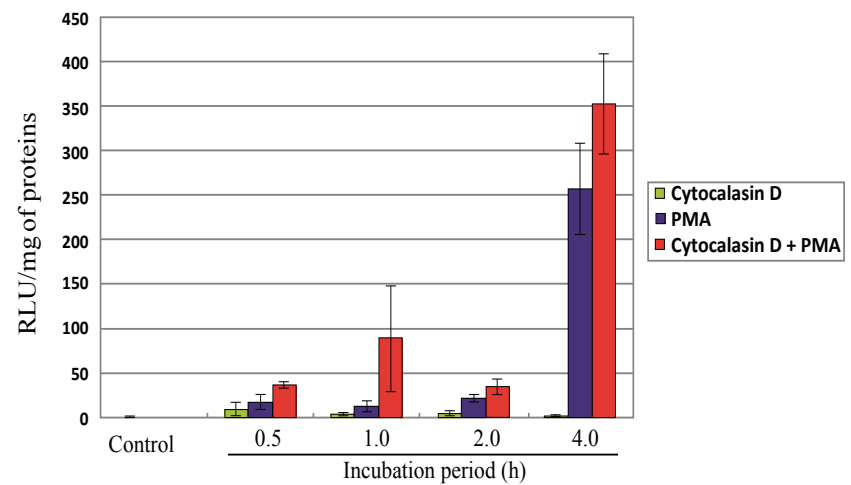

Figure 2: PMA and cytochalasin D treatment enhanced Ca-apatite mediated luciferase expression in T-leukemia cells. DNA/carbonate apatite particles were prepared by mixing $3 \mu \mathrm{l}$ of $1 \mathrm{M} \mathrm{CaCl}_{2}$ and $2 \mathrm{ug}$ of reporter plasmid DNA in $1 \mathrm{ml}$ of fresh serum-free $\mathrm{HCO}^{3-}$-buffered DMEM medium $(\mathrm{pH} \mathrm{7.5)}$, followed by incubation for $30 \mathrm{~min}$ at $37^{\circ} \mathrm{C}$ and mixing with $10 \%$ FBS and subsequently with PMA $(10 \mathrm{nM})$, cytochalasin $\mathrm{D}(1 \mu \mathrm{M})$ or both. The particle suspension was added onto Jurkat cells in each well immediately after the old RPMI medium had been removed from the well. The cells were incubated for $0.5,1,2$ and $4 \mathrm{~h}$ prior to the complete lysis of cell membrane and estimation of luciferase gene expression using a commercial kit (Promega) and photon counting (TD-20/20 Luminometer, Turner BioSystems). Each transfection experiment was done in triplicate, and transfection efficiency was expressed as mean relative light units (RLU) per milligram of cell proteins.

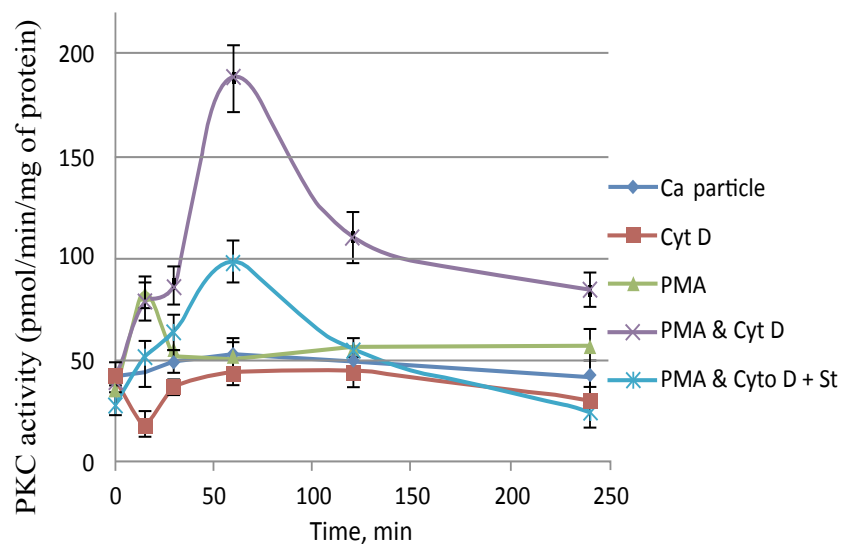

Figure 3: PKC activation levels were dramatically influenced during cellular uptake of particles in presence of PMA, cyclosporine and Cyt D. Jurkat cells were treated with the particles (formed by addition of $3 \mu \mathrm{l}$ of $1 \mathrm{M} \mathrm{CaCl}_{2}$ in 1 $\mathrm{ml}$ of $\mathrm{HCO}^{3-}$-buffered DMEM medium ( $\mathrm{pH} 7.5$ ), followed by incubation for 30 min at $37^{\circ} \mathrm{C}$ ) in presence or absence of either PMA or cytochalasin D or both PMA and cytochalsin $\mathrm{D}$ at a final concentration of $10 \mathrm{nM}$ and $1 \mu \mathrm{M}$ for PMA and cytochalasin $D$, respectively. Staurosporin (St) was added in the incubation reaction at a final concentration of $3 \mathrm{nM}$. At indicated time points medium were removed, and cells were washed 3 times with 10 mM EDTA in ice cold PBS and immediately processed for PKC activation using PKC radiometric assay kit. 
Citation: Nag K, Hossain S, Sultana N, Chowdhury EH (2013) PKC Activation Promotes Internalization of DNA-Immobilized Inorganic NanoCrystals by Clathrin-Dependent Endocytosis for Efficient Transgene Expression in Human Lymphocytes. J Nanomed Nanotechol 4: 174. doi:10.4172/2157-7439.1000174

\section{Role of PKC activation in cellular uptake of ${ }^{45} \mathrm{Ca}$-apatite particles}

To explore the role of PKC activation induced by PMA and Cyt $\mathrm{D}$ in cellular uptake of $\mathrm{Ca}^{2+}$ as a constituent of apatite particles, we synthesized carbonate apatite particles using radioactive ${ }^{45} \mathrm{Ca}$ and incubated them with Jurkat cells along with PMA and Cyt D in presence or absence of St for different periods of time (0-400 min). As shown in Figure 4, treatment with only particles caused a dramatic enhancement in intracellular ${ }^{45} \mathrm{Ca}$ starting from $15 \mathrm{~min}$ and maximizing at $240 \mathrm{~min}$ (4 h) whereas the concerted effect of PMA and Cyt D resulted in a decline of the internalized ${ }^{45} \mathrm{Ca}$ in the first hour of incubation followed by an increase with the highest peak being noticed at $2 \mathrm{~h}$, which is substantially lower than the former. Interestingly, when St was included in each of the samples, both of the highest intensity peaks shifted to the lower values with the similar trends observed at the subsequent time points (Figure 4), indicating that cellular uptake of ${ }^{45} \mathrm{Ca}$ was PKC-dependent. However, it is not still clear why the combined action of PMA and Cyt D that caused much higher induction of PKC activation than the particles only (Figure 3), resulted in lower uptake of ${ }^{45} \mathrm{Ca}$ compared to the latter.

\section{Effects of PMA and Cyt D on secretion of ${ }^{45} \mathrm{Ca}$ from internalized ${ }^{45} \mathrm{Ca}$-apatite particles}

In order to clarify the discrepancy between PKC activation and its effect disproportionately on internalization of ${ }^{45} \mathrm{Ca}$-apatite particles, we incubated Jurkat cells with either ${ }^{45} \mathrm{Ca}$-particle (Figure 5A) or ions (no particles) (Figure 5B) for $30 \mathrm{~min}$ prior to the addition of PMA and/or Cyt D. Since the action of PMA and Cyt D was made delayed for $30 \mathrm{~min}$, the consequential decline in the level of intracellular ${ }^{45} \mathrm{Ca}$ in the beginning phase (Figure 5A) was less than that observed for simultaneous incubation of particles, PMA and Cyt D with the cells (Figure 4). Treatment with PMA or Cyt D was accompanied by an increasingly higher uptake of ${ }^{45} \mathrm{Ca}$ in comparison with PMA and Cyt D (Figure 5A), although PKC activation by PMA was much less than the latter and no activation was observed for Cyt D (Figure 3). The overall declining patterns due to substantially lower values of intracellular ${ }^{45} \mathrm{Ca}$ levels for all of the samples containing $\mathrm{Ca}^{2+}$ ions only and apparently being devoid of the particles (Figure 5B) clearly indicates the dominant role of apatite particles in cellular accumulation of ${ }^{45} \mathrm{Ca}$. The initial decline in the level of intracellular ${ }^{45} \mathrm{Ca}$ due to the prior treatment with PMA and Cyt D hinted the possible roles of the these chemicals in rapid extrusion of ${ }^{45} \mathrm{Ca}$ while the subsequent increase of ${ }^{45} \mathrm{Ca}$ reflected the persistent contribution of the particles undergoing endocytosis. To prove the notion, the cells were allowed to take up ${ }^{45} \mathrm{Ca}$-particles in $1 \mathrm{~h}$ incubation time before the extracellular particles were completely removed by EDTA treatment and fresh media containing PMA and/ or Cyt D was added and kept with the cells for different periods of incubation (Figure 5C). Thus, at 0 time point, the cell population in each of the wells internalized theoretically the same number of cells and as a result, the cells treated with only nanoparticles demonstrated a gradual decrease in intracellular ${ }^{45} \mathrm{Ca}$ since there was no further uptake of the particles and the dissolved ${ }^{45} \mathrm{Ca}$ might be slowly extruded by plasma membrane-associated Ca-pump. Similar result was observed for Cyt D treatment although uptake of ${ }^{45} \mathrm{Ca}$ in presence of Cyt D was apparently lower than in its absence (i.e., particles only) in the case when particles were incubated for a consecutive period of time (Figure 5A) and this could be explained by assuming that Cyt $\mathrm{D}$ enhanced both cellular uptake of apatite particles as shown in Figure 1 [12] and extrusion of

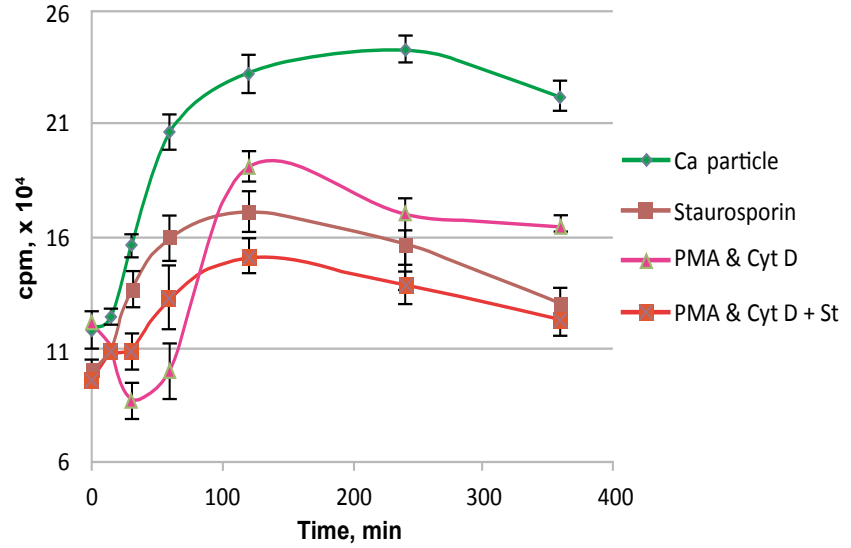

Figure 4: Inhibition of PKC activity interfered with ${ }^{45} \mathrm{Ca}$-apatite uptake in Jurkat cells. Jurkat cells were treated with generated ${ }^{45} \mathrm{Ca}$-apatite particles in presence of either PMA or cytochalasin D or both PMA and cytochalsin D at a final concentration of $10 \mathrm{nM}$ and $1 \mu \mathrm{M}$, respectively. At indicated time points medium were removed, and cells were washed 3 times with $10 \mathrm{mM}$ EDTA in ice cold PBS. Staurosporin (St) was added in the incubation reaction at a final concentration of $3 \mathrm{nM}$. Cells were immediately processed for PKC activation assay. Error bars, SEM $(n=4)$.

intracellularly dissolved ${ }^{45} \mathrm{Ca}$, although at a lower efficacy than PMA and PMA/Cyt D. However, there was an abrupt decline in the level of intracellular ${ }^{45} \mathrm{Ca}$ owing to PMA exposure while a more drastic effect was found upon exposure to both PMA and Cyt D (Figure 5C), which could be due to the fact that PMA/Cyt D combination is more effective than PMA alone in promoting efficient endocytosis of the ${ }^{45} \mathrm{Ca}$ particles and simultaneous extrusion of intracellularly released ${ }^{45} \mathrm{Ca}$ Since the combination of PMA and Cyt D is more potent than PMA alone in activating PKC (Figure 3), PKC activation seems to be the key regulatory factor in enhancing endocytosis of the apatite particles and extrusion of the intracellular Ca released from endocytosed particles.

\section{Roles of $\mathrm{Ca}^{2+}$-ATPase in extrusion of ${ }^{45} \mathrm{Ca}$ from internalized ${ }^{45} \mathrm{Ca}$-apatite particles}

To elucidate the extrusion mechanism of intracellular ${ }^{45} \mathrm{Ca}$ in Jurkat cells under the influence of PMA and Cyt D, the cells were incubated with nanoparticles in presence or absence of PMA/Cyt D and/or $\mathrm{Ln}^{3+}$, a highly specific $\mathrm{Ca}^{2+}$-ATPase blocker [20] for different periods of time prior to estimation of radio-labeled $\mathrm{Ca}$. As shown in Figure 6, treatment with $\mathrm{Ln}^{3+}$ surprisingly increased intracellular ${ }^{45} \mathrm{Ca}$ levels for PMA/Cyt D with the highest peak at $4 \mathrm{~h}$ of incubation and also for the particles (alone) with the highest peak at $2 \mathrm{~h}$, thus suggesting that $\mathrm{Ca}^{2+}$ ATPase is actively involved in removal of the intracellular ${ }^{45} \mathrm{Ca}$. The substantial difference in intracellular ${ }^{45} \mathrm{Ca}$ accumulation patterns due to inhibition of $\mathrm{Ca}^{2+}$-ATPase over periods of time $(0-6 \mathrm{~h})$ between the particles alone and the particles together with PMA/Cyt D (Figure 6) clearly indicates that the combination of PMA and Cyt D could activate $\mathrm{Ca}^{2+}$-ATPase for sequestering excessive cytosolic $\mathrm{Ca}$. Since $\mathrm{Ln}^{3+}$ could inhibit both plasmalemma and ER $\mathrm{Ca}^{2+}$-ATPases $[20,21]$, thapsigargin was used as a specific inhibitor of sarco-endoplasmic reticulum $\mathrm{Ca}^{2+}$ ATPase [22], which resulted in no change in intracellular ${ }^{45} \mathrm{Ca}$ levels for the particles in presence or absence of PMA/Cyt D, thus convincing that PMA and Cyt D facilitate extrusion of ${ }^{45} \mathrm{Ca}$ through the plasma membrane-associated $\mathrm{Ca}^{2+}$-ATPase. 
Citation: Nag K, Hossain S, Sultana N, Chowdhury EH (2013) PKC Activation Promotes Internalization of DNA-Immobilized Inorganic NanoCrystals by Clathrin-Dependent Endocytosis for Efficient Transgene Expression in Human Lymphocytes. J Nanomed Nanotechol 4: 174. doi:10.4172/2157-7439.1000174

Page 5 of 6

A

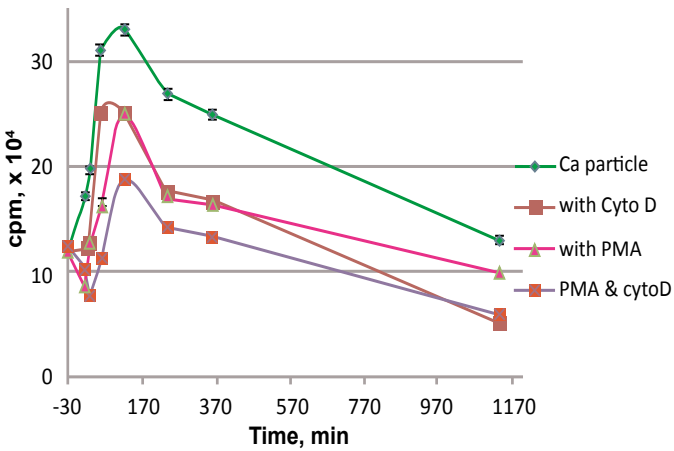

B

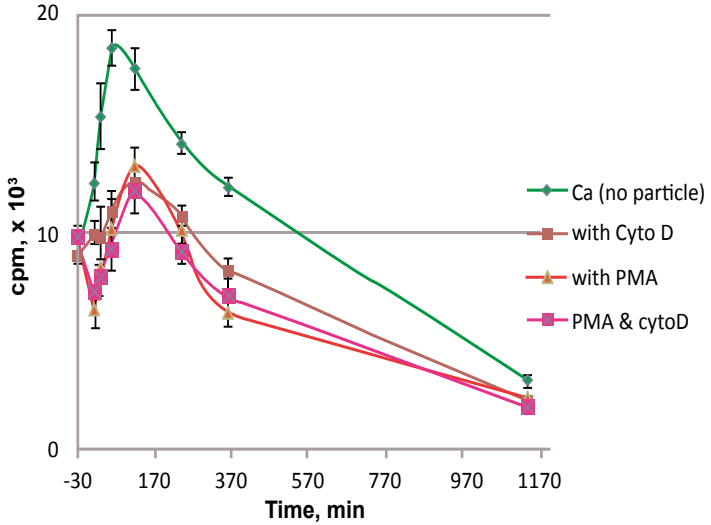

$\mathrm{C}$

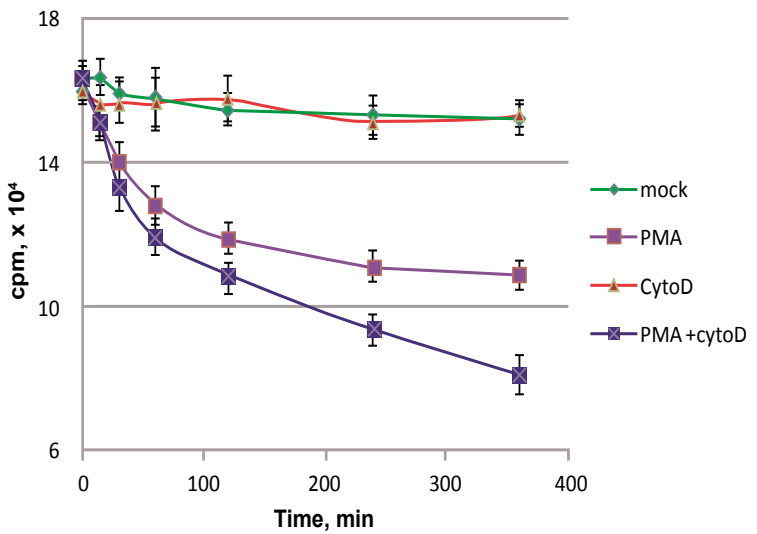

Figure 5: PMA and cytochalasin $D$ treatment enhanced $\mathrm{Ca}^{+2}$ secretion from Jurkat cells. Cells were incubated with either ${ }^{45} \mathrm{Ca}$-particle $(\mathrm{A}$, and $\mathrm{C})$ or ion (no particle) $(B)$ for either $30 \mathrm{~min}(A$, and $B$ ) or $1 \mathrm{hr}(C)$ prior to addition of the specified reagents. At indicated time points media were removed, and cells were washed 3 times with 10 mM EDTA in ice cold PBS. Samples were collected and immediately processed for radioactivity measurements. For C reagents were added after 3 times washing with 10 mM EDTA in PBS and cells were maintained in RPMI medium devoid of ${ }^{45} \mathrm{Ca}$-particle.

\section{Clathrin dependent uptake of ${ }^{45} \mathrm{Ca}$-apatite particles in presence of PMA and Cyt D}

Although nano-crystals of carbonate apatite were shown to deliver genetic materials across the membrane of primary and cancer cell lines through endocytosis [10-11], the exact route of internalization in a human lymphocyte cell line particularly under the influence of PKC activation has yet to be unveiled. Amantadine, a cationic amphiphilic drug and phenylarsine oxide (PAO), a trivalent arsenical independtly inhibit clathrin-mediated endocytosis by, respectively, stabilizing clathrin-coated vesicle and cross-linking the clathrin coat [23]. When Jurkat cells were incubated with ${ }^{45} \mathrm{Ca}$-particles for different periods of time in presence of either amantadine or PAO (Figure 7), the levels of intracellularly accumulated ${ }^{45} \mathrm{Ca}$ declined gradually with the passage of incubation time, suggesting that ${ }^{45} \mathrm{Ca}$-apatite particles are internalized by the cells in clathrin-dependent endocytosis. Almost similar finding was noticed for cellular uptake of ${ }^{45} \mathrm{Ca}$ as a constituent of apatite crystals in presence of PMA and Cyt D with significant inhibition being observed after $1 \mathrm{~h}$, indicating that clathrin-dependent rapid endocytosis of ${ }^{45} \mathrm{Ca}$-apatite particles is responsible for PKC activationinduced surge of cytoplasmic ${ }^{45} \mathrm{Ca}$ and the process of endocytosis becomes highly active after $1 \mathrm{~h}$ of incubation of the particles with cells.

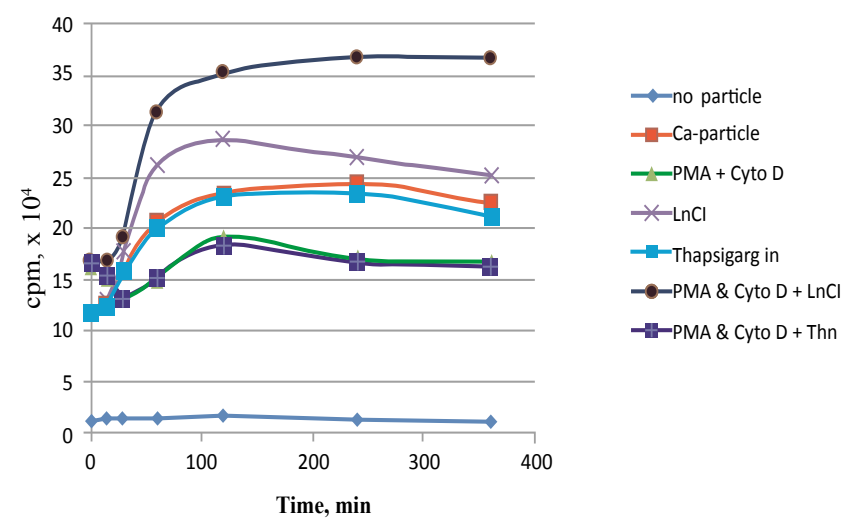

Figure 6: PMA and cytochalasin D induced $\mathrm{Ca}^{+2}$ secretion from T-leukemia cells is Ca-ATPase dependant. Jurkat cells were treated with the specified chemicals in presence of ${ }^{45} \mathrm{Ca}$-apatite. Samples were collected at indicated time points after 3 times washing with ice cold PBS, followed by 5 min incubation with $10 \mathrm{mM}$ EDTA in PBS and two times rinsing with ice cold PBS. Samples were immediately processed for radioactivity measurement. Error bar, SEM $(n=4)$; La, Lanthanum chloride; Th, thapsigargin.

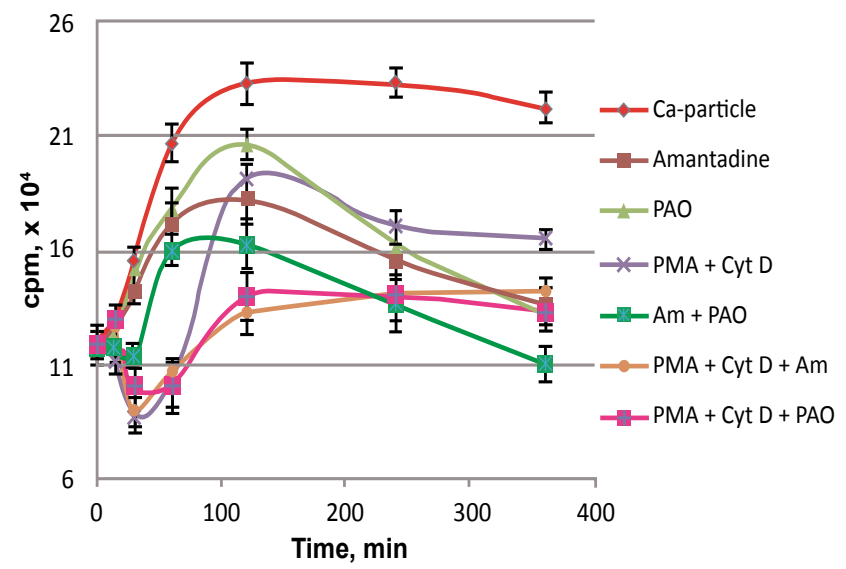

Figure 7: Uptake of ${ }^{45} \mathrm{Ca}$-apatite particles in presence or absence of PMA and Cyt $D$ was clathrin-dependent. Jurkat cells were treated with the specified chemicals in presence of ${ }^{45} \mathrm{Ca}$-apatite. Samples were collected at indicated time points after 3 times washing with ice cold PBS, followed by 5 min incubation with $10 \mathrm{mM}$ EDTA in PBS and two times rinsing with ice cold PBS. Samples were immediately processed for radioactivity measurement. Error bar, SEM $(n=4)$; Am, Amantadine; PAO, phenylarsine oxide. 
Citation: Nag K, Hossain S, Sultana N, Chowdhury EH (2013) PKC Activation Promotes Internalization of DNA-Immobilized Inorganic NanoCrystals by Clathrin-Dependent Endocytosis for Efficient Transgene Expression in Human Lymphocytes. J Nanomed Nanotechol 4: 174. doi:10.4172/2157-7439.1000174

Page 6 of 6

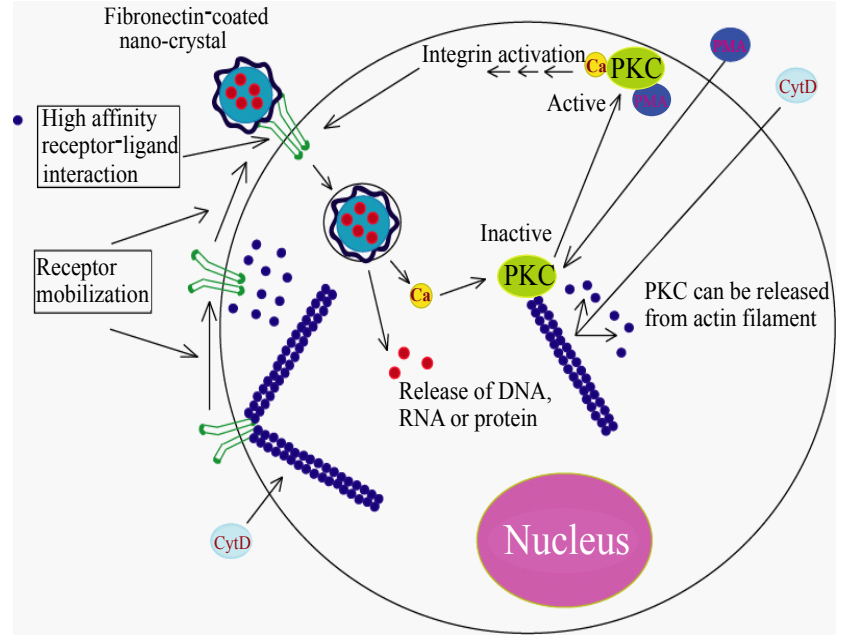

Figure 8: A proposed mechanism of synergistic effects of nano-crystals, PKC activator and actin disrupting agent on lymphocyte transfection.

\section{Conclusion}

Thus, we have established an efficient transfection process in human T leukemia cells by triggering PKC activation for rapid internalization of DNA-embedded carbonate apatite particles (Figure 8). In addition, we have elucidated the cellular mechanism for processing cytoplasmic $\mathrm{Ca}^{2+}$ released from internalized apatite particles. The study would provide invaluable insights for the development of a smart gene therapy tool in pre-clinical and clinical ex vivo trials of cancer treatment utilizing autologous $\mathrm{T}$ cells.

\section{Acnowledgement}

This work was initially supported by the Ministry of Education, Culture, Sports, Science, and Technology (MEXT, Japan) program, "Promotion of Environmental Improvement for Independence of Young Researchers", under the Special Coordination Funds for Promoting Science and Technology.

\section{References}

1. Adams SW, Emerson SG (2004) Gene therapy for leukemia and lymphoma. Hematol Oncol Clin North Am 12: 631-648.

2. Schakowski F, Buttgereit P, Mazur M, Märten A, Schöttker B, et al. (2004) Novel non-viral method for transfection of primary leukemia cells and cell lines. Genet Vaccines Ther 2: 1.

3. Szeps M, Erickson S, Gruber A, Castro J, Einhorn S, et al. (2003) Effects of interferon-alpha on cell cycle regulatory proteins in leukemic cells. Leuk Lymphoma 44: 1019-1025.

4. Finke S, Trojaneck B, Lefterova P, Csipai M, Wagner E, et al. (1998) Increase of proliferation rate and enhancement of antitumor cytotoxicity of expanded human $\mathrm{CD} 3+\mathrm{CD} 56+$ immunologic effector cells by receptor-mediated transfection with the interleukin-7 gene. Gene Ther 5: 31-39.

5. Kato K, Cantwell MJ, Sharma S, Kipps TJ (1998) Gene transfer of CD40-ligand induces autologous immune recognition of chronic lymphocytic leukemia B cells. J Clin Invest 101: 1133-1141.
6. Altenschmidt U, Klundt E, Groner B (1997) Adoptive transfer of in vitrotargeted, activated $\mathrm{T}$ lymphocytes results in total tumor regression. J Immunol 159: 5509-5515.

7. Chinnasamy D, Yu Z, Theoret MR, Zhao Y, Shrimali RK, et al. (2010) Gene therapy using genetically modified lymphocytes targeting VEGFR-2 inhibits the growth of vascularized syngenic tumors in mice. J Clin Invest 120: 3953-3968.

8. Onodera M, Ariga T, Kawamura N, Kobayashi I, Ohtsu M, et al. (1998) Successful peripheral T-lymphocyte-directed gene transfer for a patient with severe combined immune deficiency caused by adenosine deaminase deficiency. Blood 91: 30-36.

9. Haddada H, Cordier L, Perricaudet M (1995) Gene therapy using adenovirus vectors. Curr Top Microbiol Immunol 199: 297-306.

10. Chowdhury EH (2007) pH-sensitive nano-crystals of carbonate apatite for smart and cell-specific transgene delivery. Exp Opin Drug Deliv 4: 193-196.

11. Chowdhury EH, Maruyama A, Kano A, Nagaoka M, Kotaka M, et al. (2006) pHsensing nano-crystals of carbonate apatite: effects on intracellular delivery and release of DNA for efficient expression into mammalian cells. Gene 376: 87-94.

12. Kutsuzawa K, Tada S, Hossain S, Fukuda K, Maruyama K, et al. (2009) Disrupting actin filaments promotes efficient transfection of a leukemia cell line using cell adhesive protein-embedded carbonate apatite particles. Anal Biochem 388: 164-166.

13. Chowdhury EH, Nagaoka M, Ogiwara K, Zohra FT, Kutsuzawa K, et al. (2005) Integrin-supported fast rate intracellular delivery of plasmid DNA by extracellular matrix protein embedded calcium phosphate complexes. Biochemistry 44 12273-12278.

14. Chowdhury EH (2005) Self-assembly of DNA and cell-adhesive proteins onto $\mathrm{pH}$-sensitive inorganic crystals for precise and efficient transgene delivery. Curr Pharm Des 14: 2212-2228.

15. Chowdhury EH, Akaike T (2005) Mammalian Integrin-targeted gene delivery: A common approach for advanced viral and non-viral vectors. Gene Ther Mol Biol 9: 431-444.

16. Hayman EG, Ruoslahti E (1979) Distribution of fetal bovine serum fibronectin and endogenous rat cell fibronectin in extracellular matrix. J Cell Biol 83: 255259.

17. Cervino MC, Lopez-Lago MA, Vinuela JE, Barja P (2010) Specific inhibition of protein kinase Cbeta expression by antisense RNA affects the activation of Jurkat T lymphoma cells. J Biol Regul Homeost Agents 24: 273-285.

18. Hauzenberger D, Sundqvist KG (1993) Fibronectin at the lymphocyte surface. Evidence for activation-dependent binding to VLA4 and VLA5 integrins. Scand $\mathrm{J}$ Immunol 37: 87-95.

19. Teixé T, Nieto-Blanco P, Vilella R, Engel P, Reina M, et al. (2008) Syndecan-2 and -4 expressed on activated primary human $C D 4+$ lymphocytes can regulate T cell activation. Mol Immunol 45: 2905-2919.

20. Wu ML, Chen JH, Chen WH, Chen YJ, Chu KC (1999) Novel role of the Ca(2+)ATPase in NMDA-induced intracellular acidification. Am J Physiol 277: C71727.

21. Fujimori T, Jencks WP (1990) Lanthanum inhibits steady-state turnover of the sarcoplasmic reticulum calcium ATPase by replacing magnesium as the catalytic ion. J Biol Chem 265: 16262-16270.

22. Treiman M, Caspersen C, Christensen SB (1998) A tool coming of age: thapsigargin as an inhibitor of sarco-endoplasmic reticulum $\mathrm{Ca}(2+)$-ATPases. Trends Pharmacol Sci 19: 131-135.

23. Rückert $P$, Bates SR, Fisher $A B$ (2003) Role of clathrin- and actin-dependent endocytotic pathways in lung phospholipid uptake. Am J Physiol Lung Cell Mol Physiol 284: L981-L989. 